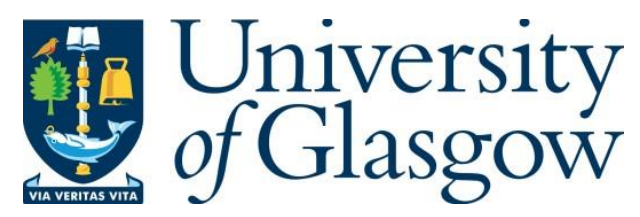

Georgiev, V. P., Vila-Nadal, L., Cronin, L. and Asenov, A. (2018) Molecular Based Flash Cell for Low Power Flash Application: Optimization and Variability Evaluation. In: IEEE 12th Nanotechnology Materials and Devices Conference (NMDC 2017), Singapore, 2-4 Oct 2017, pp. 64-65. ISBN 9781538627723.

There may be differences between this version and the published version. You are advised to consult the publisher's version if you wish to cite from it.

$\underline{\text { http://eprints.gla.ac.uk/164638/ }}$

Deposited on: 27 July 2018

Enlighten - Research publications by members of the University of Glasgow http://eprints.gla.ac.uk 


\title{
Molecular based flash cell for low power flash application: optimization and variability evaluation
}

\author{
Vihar P. Georgiev Member, IEEE, Laia Vilà-Nadal, Leroy Cronin and Asen Asenov, Fellow, IEEE
}

\section{INTRODUCTION}

The field of molecular electronics continues to spur interest in the quest for miniaturization and reduction of operational power of electron devices. Most of the systems described in the literature are based on organic molecules, such as benzene, ferrocene and fullerenes ${ }^{[1]}$. However, the use of inorganic molecules known as polyoxometalates (POMs) (see Fig.1 and Fig.2) could offer several important advantages over the conventional and organic based devices. Our present work shows that POMs are more compatible with existing CMOS processes than organic molecules and they can replace the polysilicon floating gate in contemporary flash cell devices ${ }^{[2]}$. The interest in POMs for flash cell applications stems from the fact that POMs are highly redox active molecules and that they can also be doped with electronically active heteroatoms ${ }^{[3]}$. They can undergo multiple reversible reductions/oxidations, which makes them attractive candidates for multi-bit storage in flash memory cells. The molecular charge storage is localised, thus minimising cross-cell capacitive coupling, which arises from charge redistribution on the sides of a poly-Si floating gate (FG) and is one of the most critical issues with flash memories. Although this benefit is presently realised in floating gates by charge-trapping dielectric or by a metallic nano-cluster array, both technologies exhibit large variability. Charge-trap memories suffer variation in trapdensity and trap energy and the size and density of nanoclusters is difficult to control. This precludes their ultimate miniaturization. In fact, the concept of using molecules as storage centers has already been demonstrated for organic redox-active molecules ${ }^{[1]}$. Here, using full $3 \mathrm{D}$ simulations, we evaluate correlation between the device performance (in terms of threshold voltage $\mathrm{V}_{\mathrm{T}}$ ) and statistical variability, arising from the random dopant fluctuations (RDF) and POM fluctuations (POMF).

\section{Simulation Methodology And Cell Design}

In order to evaluate the performance of POMs as storage centers in the floating gate (FG) in flash cell memories, we develop a simulation flow that links the density functional theory (DFT) to a three-dimensional (3D) numerical simulator ${ }^{[4]}[5]$. The main advantage of that framework is that once the charge for the POM is obtained from the DFT program and it is transferred to the $3 \mathrm{D}$ numerical TCAD simulator, a drift-diffusion transport formalism is applied. It

Research is supported by the UK EPSRC platform grant EP/H024107/1.

Vihar P. Georgiev and Asen Asenov are with the Device Modelling Group, School of Engineering, University of Glasgow, G12 8LT, Glasgow, UK.

Laia Vilà-Nadal and Leroy Cronin are with WestCHEM, School of Chemistry, University of Glasgow, G12 8QQ, Glasgow, UK.

Corresponding author: Vihar.Georgiev@glasgow.ac.uk

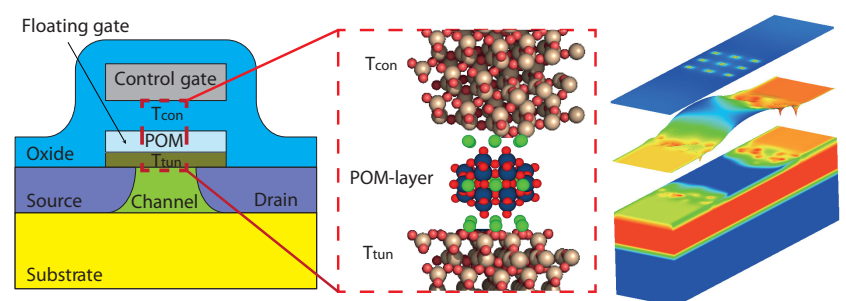

Fig. 1 Left - Schematic representation of a single-transistor FDSOI nonvolatile memory cell, indicating the aimed substitution of the poly-Si floating gate (FG) with an array of polyoxometalate clusters (POM layer). The green balls are point charges representing the cations, which surround each POM in the experiment. Right $-3 \mathrm{D}$ electrostatic potential in oxide and the substrate. Fingerprint of the $3 \times 3$ POMs in the gate and the random dopant in the source and the drain are clearly visible.

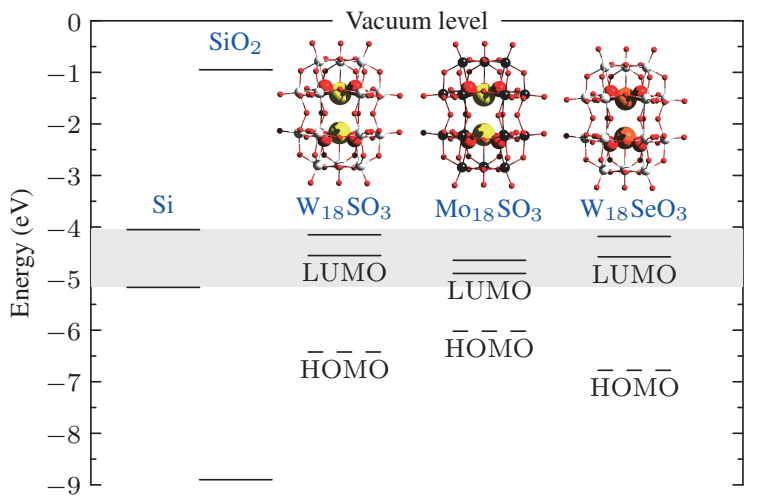

Fig. 2 Energy diagram comparing the conduction and valence band edges of $\mathrm{Si}$ and $\mathrm{SiO}_{2}$ relative to the HOMO and LUMO levels of three POMs. Balland-stick view (insert) of three non-classic Wells-Dawson structures $\mathrm{W}_{18} \mathrm{SO}_{3}$ - $\left[\mathrm{W}_{18} \mathrm{O}_{54}\left(\mathrm{SO}_{3}\right)_{2}\right]^{4-} ; \mathrm{M}_{18} \mathrm{SO}_{3}-\left[\mathrm{M}_{18} \mathrm{O}_{54}\left(\mathrm{SO}_{3}\right)_{2}\right]^{4-}$ and $\mathrm{W}_{18} \mathrm{SeO}_{3}$ $\left[\mathrm{W}_{18} \mathrm{O}_{54}\left(\mathrm{SeO}_{3}\right)_{2}\right]^{4-}$.

includes quantum corrections by means of the densitygradient approach. In this way the computation flow has capabilities to evaluate not only the material capabilities but also the device performance.

The key design parameters of our template flash memory cell are based on our recent publication ${ }^{[6]}$. For the purpose of this study, an n-channel FDSOI flash memory cell with an 18 nm square gate has been designed (Fig.1). It is based on a previously studied $18 \mathrm{~nm}$ 'template' transistor and it is similar to the contemporary flash cells studied elsewhere.

Fig. 2 shows a key result of the DFT calculations for three POM clusters. The energy levels of the highest occupied and lowest unoccupied molecular orbitals (HOMO and LUMO, respectively) for all molecules are favourably aligned below the conduction band of Si and they could be effectively insulated by a comparatively high potential barrier of $\mathrm{SiO}_{2}$. From this point of view all three molecules are similar, however only the $\mathrm{W}_{18} \mathrm{SeO}_{3}-\left[\mathrm{W}_{18} \mathrm{O}_{54}\left(\mathrm{SeO}_{3}\right)_{2}\right]^{4-}$ cluster shows numerous oxidation and reduction properties ${ }^{[2 a]}$. As a result, 
in this work we concentrate our discussions on this specific molecule $-\mathrm{W}_{18} \mathrm{SeO}_{3}$.

\section{STATISTICAL VARIABILITY}

In order to obtain realistic results for threshold voltage variability in the FDSOI flash cell with POM molecules as a storage media, we introduce three sets of 1,000 devices. Each set has two sources of statistical variability, such as random dopant fluctuations (RDF) and POMs fluctuations (POMF). We incorporate the charge density of nine $\left[\mathrm{W}_{18} \mathrm{O}_{54}\left(\mathrm{SeO}_{3}\right)_{2}\right]^{4-}$ POMs (shown in Fig.1) as a charge storage center. It should be emphasised that for all three sets of 1,000 devices composing the ensembles, the number of POMs is constant and it equals nine. In the case of the RDF only calculations, the charge storage clusters are arranged in a regular grid of $3 \times 3$ POMs centered within the gate (right hand side of Fig.1). In the POMF only calculations, the molecules are randomly displaced laterally in relation to the regular $3 \times 3$ grid used previously. Finally, in the third case, both of these variations, i.e., RDF and POMF, are included.

Four distinct $V_{T}$ values related to the four easily accessible oxidation/reduciton states of the molecular cluster can be obtained. Fig.3, Fig.4 and Fig.5 present the probability density function (PDF) and standard deviation $(\sigma)$ for an ensemble of 1,000 devices with RDF only, POMF only and RDF + POMF, correspondingly. Based on our numerical calculations displayed above, we can draw the following important conclusions.

Firstly, the curves presenting the PDF for all devices with RDF (Fig.3 and Fig.5) are broader in comparison to the POMFs only case (Fig.4). This is reflected in the values of the standard deviation shown where all flash cells with RDF+POMF have standard deviation of around $100 \mathrm{mV}$, while in the case of the POMF only calculations this value varies from 0 to $63 \mathrm{mV}$. Hence, it can be concluded that the RDF has stronger impact on the $\sigma \mathrm{V}_{\mathrm{T}}$ in comparison to the POMF only scenario. Also, in all calculations the results fit well with the Gaussian distribution (dashed line in Fig.3 Fig.5).

Secondly, the average value of $V_{T}$ for each bit has higher values in comparison to the average values of $\mathrm{V}_{\mathrm{T}}$ for the $\mathrm{RDF}$ only, POMF and RDF+POMF cells. Also, the standard deviation increases in the RDF cells with increasing of the redox state of the molecule and $\sigma$ increases with the increase of the negative charge in the POM. This dependence is much stronger and it is reflected in the RDF+POMF ensemble too.

Thirdly the average value of $\mathrm{V}_{\mathrm{T}}$, needed for the cell to change the oxidation state by one electron for each POM is $0.96 \mathrm{~V}$ and $0.84 \mathrm{~V}$. In the case of the RDF, POMF $\mathrm{RDF}+\mathrm{POMF}$ structures the $\mathrm{V}_{\mathrm{T}}$ steps are almost identical and they are around $0.74 \mathrm{~V}$ and $0.83 \mathrm{~V}$ for the first and the second step of oxidation, respectively.

In conclusion, in this work we compare the statistical threshold voltage variability of the molecular based $18-\mathrm{nm}$ FDSOI flash cells. Two sources of statistical variability, RDF and POMF, are discussed. Also, we establish that the RDF variability is the dominant factor that influences the $V_{T}$ distribution. Moreover, our approach provides both qualitative and quantitate inside toward the design and optimisation of such molecular-based flash cell, particularly in the context of sources of statistical variability.
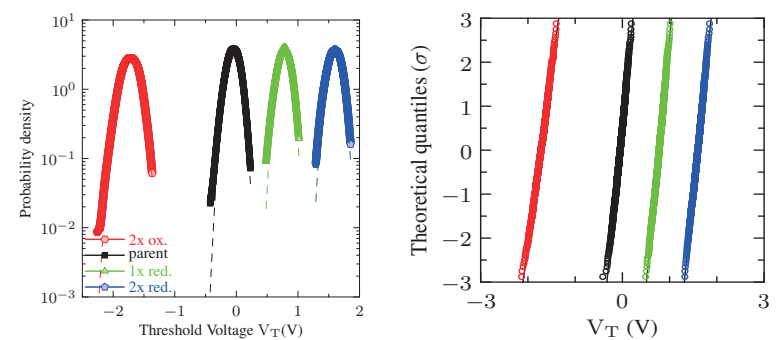

Fig. 3 Left: Probability density function (PDF); Right: normal probability plot of the same distribution function of the $\mathrm{V}_{\mathrm{T}}$ distribution for each bit of 1,000 devices with RDF only. Dashed line is a Gaussian fit.
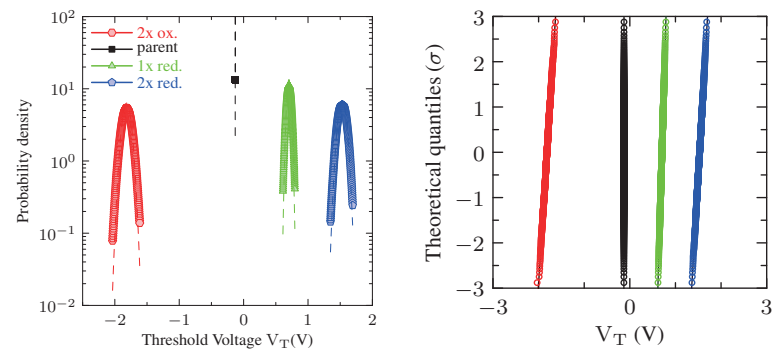

Fig. 4 Left: Probability density function (PDF); Right: normal probability plot of the same distribution function of the $\mathrm{V}_{\mathrm{T}}$ distribution for each bit of 1,000 devices with POMF only.
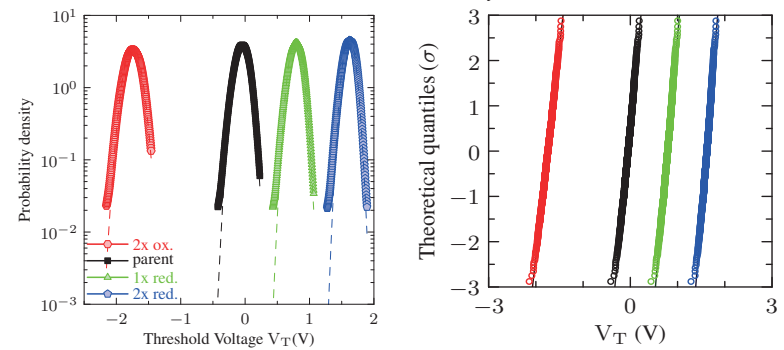

Fig. 5 Probability density function (PDF); Right: normal probability plot of the same distribution function of the $\mathrm{V}_{\mathrm{T}}$ distribution for each bit of 1,000 devices with combined variability ( $R D F$ with $P O M F)$.

\section{REFERENCES}

[1] H. Zhu and Q. Li, Applied Sciences 2015, 6, 7.

[2] a) C. Busche, L. Vilà-Nadal, J. Yan, H. N. Miras, D. L. Long, V. P. Georgiev, A. Asenov, R. H. Pedersen, N. Gadegaard, M. M. Mirza, D. J. Paul, J. M. Poblet and L. Cronin, Nature 2014, 515, 545-549; b) V. P. Georgiev, S. M. Amoroso, T. M. Ali, L. Vila-Nadal, C. Busche, L. Cronin and A. Asenov, IEEE Transactions on Electron Devices 2015, 62, 680-684; c) V. P. Georgiev, S. M. Amoroso, L. Vila-Nadal, C. Busche, L. Cronin and A. Asenov, Proceedings of the 2014 44th European Solid-State Device Research Conference (Essderc 2014) 2014, 353-356; d) V. P. Georgiev, S. Markov, L. Vilà-Nadal, C. Busche, L. Cronin and A. Asenov, 2013 Proceedings of the European Solid-State Device Research Conference (Essderc) 2013, 230-233.

[3] D. L. Long, R. Tsunashima and L. Cronin, Angew Chem Int Ed Engl 2010, 49, 1736-1758.

[4] V. P. Georgiev and A. Asenov in Multi-scale Computational Framework for Evaluating of the Performance of Molecular Based Flash Cells, Eds.: I. Dimov, S. Fidanova and I. Lirkov), Springer International Publishing, Cham, 2015, pp. 196-203.

[5] L. Vilà-Nadal, S. G. Mitchell, S. Markov, C. Busche, V. Georgiev, A. Asenov and L. Cronin, Chemistry - A European Journal 2013, 19, 1650216511.

[6] V. P. Georgiev, S. Markov, L. Vila-Nadal, C. Busche, L. Cronin and A. Asenov, IEEE Transactions on Electron Devices 2014, 61, 2019-2026. 